NBER WORKING PAPER SERIES

\title{
E-CIGARETTES AND ADULT SMOKING: EVIDENCE FROM MINNESOTA
}

\author{
Henry Saffer \\ Daniel L. Dench \\ Michael Grossman \\ Dhaval M. Dave \\ Working Paper 26589 \\ http://www.nber.org/papers/w26589 \\ NATIONAL BUREAU OF ECONOMIC RESEARCH \\ 1050 Massachusetts Avenue \\ Cambridge, MA 02138 \\ December 2019
}

This project was funded by grant number R01-DA039968 entitled "The Economics of Electronic Nicotine Delivery Systems: Advertising and Outcomes", from the National Institute of Health to the National Bureau of Economic Research, Inc. This study employs data from the A.C. Nielsen Company, which was purchased from the Kilts Center of the University of the Chicago Booth School of Business. Results are calculated (or derived) based on data from The Nielsen Company (US), LLC and marketing databases provided by the Kilts Center for Marketing Data Center at The University of Chicago Booth School of Business. Information about the data and access are available at http://research.chicagobooth.edu/nielsen/. We are grateful to the A.C. Nielsen Company and the Kilts Center for providing the data and for instructions in its use. The conclusions drawn from the Nielsen data are those of the researchers and do not reflect the views of Nielsen. Nielsen is not responsible for, had no role in, and was not involved in analyzing and preparing the results reported herein. Copyright () 2017. The Nielsen Company (US), LLC. All Rights Reserved. The views expressed herein are those of the authors and do not necessarily reflect the views of the National Bureau of Economic Research.

NBER working papers are circulated for discussion and comment purposes. They have not been peer-reviewed or been subject to the review by the NBER Board of Directors that accompanies official NBER publications.

(C) 2019 by Henry Saffer, Daniel L. Dench, Michael Grossman, and Dhaval M. Dave. All rights reserved. Short sections of text, not to exceed two paragraphs, may be quoted without explicit permission provided that full credit, including $\odot$ notice, is given to the source. 
E-Cigarettes and Adult Smoking: Evidence from Minnesota

Henry Saffer, Daniel L. Dench, Michael Grossman, and Dhaval M. Dave

NBER Working Paper No. 26589

December 2019

JEL No. I12,I18

\section{ABSTRACT}

E-cigarettes use a battery powered heater to turn a liquid containing nicotine into a vapor. The vapor is inhaled by the user and is generally considered to be less harmful than the smoke from combustible cigarettes because the vapor does not contain the toxins that are found in tobacco smoke. Because e-cigarettes provide an experience that is very similar to smoking, they may be effective in helping smokers to quit, and thus the availability of e-cigarettes could increase quit rates. Alternatively, e-cigarettes may provide smokers with a method of bypassing smoking restrictions and prolong the smoking habit. There is very little causal evidence to date on how ecigarette use impacts smoking cessation among adults. Although there is no federal tax on ecigarettes, a few states have recently imposed heavy taxes on them. We provide some of the first evidence on how e-cigarette taxes impact adult smokers, exploiting the large tax increase in Minnesota. That state was the first to impose a tax on e-cigarettes by extending the definition of tobacco products to include e-cigarettes. This tax, which is $95 \%$ of the wholesale price, provides a plausibly exogenous deterrent to e-cigarette use. We utilize data from the Current Population Survey Tobacco Use Supplements from 1992 to 2015, in conjunction with a synthetic control difference-in-differences approach. We assess how this large tax increase impacted smoking cessation among adult smokers. Estimates suggest that the e-cigarette tax increased adult smoking and reduced smoking cessation in Minnesota, relative to the control group, and imply a cross elasticity of current smoking participation with respect to e-cigarette prices of 0.13 . Our results suggest that in the sample period about 32,400 additional adult smokers would have quit smoking in Minnesota in the absence of the tax. If this tax were imposed on a national level about 1.8 million smokers would be deterred from quitting in a ten year period. The taxation of e-cigarettes at the same rate as cigarettes could deter more than 2.75 million smokers nationally from quitting in the same period. The public health benefits of not taxing e-cigarettes, however, must be weighed against effects of this decision on efforts to reduce vaping by youth.

\section{Henry Saffer}

National Bureau of Economic Research

5 Hanover Square, 16th Floor

Suite 1602

New York, NY 10004-2630

hsaffer@gc.cuny.edu

Daniel L. Dench

The Graduate Center, CUNY

365 Fifth Avenue

New York, NY 10016

danieldench1@gmail.com
Michael Grossman

National Bureau of Economic Research

5 Hanover Square, 16th Floor

Suite 1602

New York, NY 10004-2630

and City University of New York

Graduate Center

and IZA

mgrossman@gc.cuny.edu

Dhaval M. Dave

Bentley University

Department of Economics

175 Forest Street, AAC 195

Waltham, MA 02452-4705

and IZA

and also NBER

ddave@bentley.edu 


\section{Introduction}

A number of battery-powered devices on the market today deliver nicotine to the user in an aerosol or vapor form and are referred to as electronic cigarettes (e-cigs). Use of e-cigs is often called vaping in contrast to smoking conventional combustible cigarettes. ${ }^{1}$ Because e-cigs are a relatively new product, there is no research on the long-term health effects of use. Nevertheless, e-cigs are generally considered to be less harmful than combustible cigarettes because the vapor produced by them does not contain the toxins and nitrosamines that are found in tobacco smoke (Goniewicz et al. 2013; Czogala et al. 2014). The U.S. National Institute on Drug Abuse states that because e-cigs deliver nicotine without burning tobacco, they appear to be a safer, less toxic alternative to conventional cigarettes. ${ }^{2}$ Public Health England, a public health agency within the U.K.'s Department of Health and Social Care, has taken a more definitive position and stated that e-cigs are significantly less harmful to health and are about 95 percent safer than smoking (McNeil et al. 2015).

The public health debate surrounding the regulation of e-cigs has centered on harms to non-smoking adolescents and harm reduction for adults who smoke. For adolescents the concern is that e-cig use may have negative effects on cognitive development, result in long term nicotine addiction, and may lead to conventional cigarette use. For those adolescents who wish to experiment with nicotine, e-cigs may be a safer option than cigarettes and may have contributed to the decline in adolescent smoking. E-cigs may be effective in helping adult smokers to quit the habit. Currently between 14-19 percent of adults continue to use cigarettes (2017, National Health Interview Survey, NHIS and National Survey of Drug Use and Health, NSDUH), and interest in quitting smoking remains high. Almost two-thirds of current smokers report that they want to quit smoking completely, and among those who expressed such an intent about 60 percent follow-up with an actual cessation attempt (NHIS 2015). However, most

\footnotetext{
${ }^{1}$ All e-cigs have certain components in common, including a power source or battery that heats a liquid (usually propylene glycol) containing nicotine into an aerosol that is then inhaled by the user. 2 See https://www.drugabuse.gov/publications/drugfacts/electronic-cigarettes-e-cigs.
} 
attempts end in relapse, and less than one in ten smokers overall successfully quit in the past year (Babb et al. 2017). ${ }^{3}$ E-cigs may be an effective substitute for smoking, particularly for smokers who have had a difficult time quitting in the past through other methods. Thus, the accessibility of e-cigs might enhance smoking cessation rates. On the other hand, it is also possible, as some contend, that e-cig use may adversely impact smoking cessation by undermining smoking restrictions and providing smokers with an alternative nicotine source for situations where smoking is not permitted.

This paper focuses on the potential for harm reduction for adults. There is very little causal evidence to date on how e-cig use impacts smoking cessation among adults. Acknowledging the potential for e-cigs to help smokers quit along with limited empirical evidence on this issue, the Food and Drug Administration (FDA) has thus far refrained from regulating their access for adults. For instance, unlike conventional cigarettes, e-cig manufacturers continue to be able to advertise in broadcast media, and the FDA has resisted banning or restricting such advertising. The FDA has also postponed for now the requirement that e-cig manufacturers submit marketing applications, a condition which would otherwise have effectively banned all e-cig products from the market until the FDA reviewed and approved the applications. ${ }^{4}$

In contrast to the FDA's relatively more accommodative stance at least with respect to adult access, a growing number of state and local governments have taken steps to more forcefully regulate the sale, marketing, and use of e-cigs. Attorneys General for 29 states signed a letter in 2014 urging the FDA to regulate the sale of e-cigs and restrict its advertising and marketing. ${ }^{5}$ By the time the federal e-cig minimum legal sale age law of 18 went into effect in August of 2016, all states but two had a similar law in place. As of June 2019, 15 states

\footnotetext{
${ }^{3}$ In general, less than one in four cessation attempts is successful. For the average smoker, the expected number of quit attempts before quitting smoking successfully has been estimated as ranging from 6 to 30 attempts (Chaiton et al. 2016).

${ }^{4}$ While the FDA continues to make e-cigs available and accessible in the market for adults, it has taken a more aggressive approach towards regulating access for youth and educating them about the dangers of e-cigs.

${ }^{5}$ See https://ag.ny.gov/pdfs/FINAL AG FDA Comment Re Deeming Regulations.pdf.
} 
raised their e-cig minimum purchase age to 21 . An increasing number of states are also requiring licenses for retail sales of e-cigs and are expanding their smoking bans and clean indoor air laws to include vaping. Several states have also banned sales of flavored e-cigs and Walmart has announced that it will end sales of all e-cigs.

There is no federal tax on e-cigs, unlike on cigarettes and other tobacco products. With e-cigs being relatively new, states have struggled to determine whether and how to tax them. As of the end of 2018, ten states (in addition to several cities and counties) had started to levy taxes on e-cigs or the liquid nicotine used with e-cigs. Nine additional states began to do so in 2019 and two more will follow suit in 2020 (Campaign for Tobacco-Free Kids 2019). Given that one aspect of tobacco taxes is to improve public health and reduce tobacco-related health expenditures, there exists a key knowledge gap in the literature to inform policymakers contemplating taxes on e-cigs. It remains unclear how e-cig taxes impact smoking cessation. If higher e-cig taxes dissuade adult smokers from shifting to vapor products and from quitting smoking in the process, the forgone harm reduction must be taken into account; this would provide justification for taxing e-cigs less than traditional tobacco products, if at all. Similarly, if e-cig taxes promote smoking cessation, by making it more difficult for smokers to circumvent smoking restrictions and by reducing the overall addictive stock of nicotine, then this would provide additional rationale for levying taxes on e-cigs at the federal and state levels.

Our study directly addresses this knowledge gap, and makes several contributions in the process. We provide some of the first rigorous evidence on how taxing e-cigs impacts smoking cessation among adults. The empirical analysis exploits the large e-cig tax hike in Minnesota $(\mathrm{MN})$, the first state to tax e-cigs, in conjunction with a synthetic control difference-in-differences approach to identify plausibly causal effects of e-cig use on adult smoking. In addition to providing direct estimates of the cross-effects of e-cig taxation, we also add to the very limited evidence base on the substitution and complementarity between e-cigs and cigarettes. We find consistent evidence that higher e-cig taxes increase adult smoking rates and reduce quits, implying that e-cigs are a likely substitute for conventional cigarettes among current smokers. 
The remainder of the paper proceeds as follows. The next section briefly provides some background on the previous literature. Section 3 details the data and the empirical methods that we apply to this question, following by a discussion of the results. The concluding section summarizes our findings and places them in context along with some policy implications.

\section{Background}

Much of the literature that has considered the relationship between e-cig use and smoking among adults has relied on correlational evidence and not addressed the endogeneity between both behaviors. ${ }^{6}$ The evidence from these sets of studies should be interpreted as descriptive and is fairly mixed. Several studies find that e-cig use is associated with reduced smoking. Zhu et al. (2017) analyze data from the Tobacco Use Supplements of the Current Population Surveys. They find that the population smoking cessation rate for 2014-2015 was significantly higher than for 2010-2011, coinciding with an increase in e-cig use. Exploiting information on e-cig use from the 2014-2015 wave, they also find that e-cig users were more likely than non-users to attempt to quit and more likely to succeed in quitting (defined as abstinence for 3 months or longer). Zhuang et al. (2016) conduct a two-year follow up of 2097 adult smokers, who were initially sampled using GfK's Knowledge Panel in 2012. Comparing short-term e-cig users (used in 2012 but not 2014) vs. long-term e-cig users (used e-cigs in both 2012 and 2014) vs. non-users, they find that long-term e-cig users had a higher quit attempt rate as well as a higher successful quit rate relative to both non-users and short-term e-cig users. A common pattern in tobacco consumption is dual cigarette and e-cig use, and there is some concern that prolonged dual use might impede or postpone the attempt to quit smoking. Zhuang et al. (2016) do not find, however, that dual use is associated with a lower smoking cessation rate.

\footnotetext{
${ }^{6}$ In this case, the endogeneity can reflect both reverse causality with e-cig use affecting smoking and vice versa as well as selection on unobserved factors (for instance, a propensity for addictive behaviors, risk tolerance, time preference) that may affect participation in both behaviors.
} 
Brown et al. (2014) assessed the effectiveness of e-cigs when used to aid smoking cessation, in comparison with nicotine replacement therapy (NRT) and with unaided quitting. They rely on a cross-sectional survey of the English population that includes 5863 adults who had smoked within the previous 12 months and made at least one quit attempt during that period with either e-cigs, NRT or no aid. Their results show that e-cig users were more likely to report smoking abstinence (defined as non-smoking status at time of survey) than either those who used NRT or no aid.

Grana, Benowitz, and Glantz (2014) contend that although e-cig use may reduce smoking, it also may inhibit complete smoking cessation. They note that while some smokers cite a desire to quit smoking through the use of e-cigs, other common reasons given by smokers who also vape are to circumvent smoke-free laws and to cut down on conventional cigarettes. This may reinforce dual use patterns and delay or deter quitting. Kalkhoran and Glantz (2016) provide a review of papers that attempt to assess the relationship between e-cig use and smoking cessation by adult smokers. The question they are interested in is whether cigarette smokers who report e-cig use have a higher or lower probability of quitting smoking. Summarizing evidence from 38 studies, and performing a meta-analysis of 20 studies with control groups (most of these are cross-sectional or cohort studies), they conclude that the odds of quitting cigarettes were about 28 percent lower among e-cig users compared with non-users. Weaver et al. (2018) conduct a prospective cohort study, recruiting 1284 U.S. adult smokers in mid-2015 and following up with them about one year later. The odds of quitting smoking were found to be significantly lower among smokers who used e-cigs at baseline compared to smokers who did not vape. Smokers who had used e-cigs at some point during the study period were also less likely to quit smoking (defined as abstinence for at least 30 days prior to follow-up) relative to non-users. These studies are correlational rather than causal and cannot account for unmeasured confounders.

Huang et al. (2014), Zheng et al. (2016, 2017), and Tuchman (2019) provide evidence of causal effects of e-cigarette use on cigarette smoking in a reduced form setting. They do so by 
examining the impact of changes in the price of one good on the use of the other one. If, for example, the two goods are substitutes (a reduction in the price of one leads to a reduction in use of the other) that would suggest that an increase in e-cigarette use causes a reduction in smoking. All four studies employ Nielsen ScanTrack, which contains store scanner data at the point of sales, from 2009 or 2010 through 2012, 2013, or 2015 depending on the study. Except for Zheng et al. (2016), these studies find that the two goods are substitutes.

Several problems arise in this line of research. Price is computed by dividing sales revenue by sales in physical units. This introduces bias in the regression models because price and sales are not measured independently. Indeed, the own-price elasticity of demand for cigarettes in these studies usually is larger than one in absolute value, which is much larger than any of those in the previous literature reviewed by Cawley and Ruhm (2012). This problem aside, the demand functions may be subject to simultaneity bias due to the presence of an upward-sloping supply function in a competitive model or due to the behavior of firms in oligopolistic markets. Moreover, given that e-cigs are a new product, retailers may have incentives to begin to sell the product in areas where demand for it is expected to be substantial. Finally, e-cig sales in 2009, 2010, and 2011 were very limited. Consequently the price data for e-cigs in those years may be inaccurate.

Cotti, Nesson, and Teft (2018) overcome some of the issues just discussed by exploiting within-state variation in cigarette excise taxes to measure effects on e-cig and cigarette use from the Nielsen Homescan Panel, which contains actual purchases made by households, from 2011 through 2015. Cigarette taxes are not subject to measurement error and can reasonably be assumed to be exogenous in cigarette and e-cig demand functions. They find that higher cigarette taxes decrease both cigarette and e-cig purchases, suggesting that cigarettes and ecigs are complements. Because e-cigs are a relatively new product, the sample period is short, which limits the identifying variation in cigarette taxes. This may have contributed to their finding of very large elasticity estimates $(-1.9$ to -2.6$)$ of purchases of e-cig refills and starter kits with respect to the cigarette excise tax. Furthermore, because these are tax elasticities, the 
implied elasticities with respect to cigarette price are higher in magnitude. This study does not directly consider effects of e-cig taxes.

Pesko, Courtemanche and Maclean (2019) extend the previous study by examining the effects of e-cigarette taxes as well as those of cigarette taxes on smoking and vaping participation by adults. They employ a dichotomous variable for the adoption of any type of tax on e-cigs, which conflates very different tax schemes (ad valorem vs. excise; very small and relatively large taxes). These different approaches to state e-cig taxation policy have resulted in a trivial effect on price in some states and a large effect on price in other states. Pesko et al. (2019) use data from the Behavioral Risk Factor Surveillance System and the National Health Interview Surveys between 2011 and 2017 in conjunction with a difference-in-differences model. This sample period excludes Minnesota, which had the largest e-cig tax, from the within-state identifying variation because the state had a tax on e-cig in place for the entire sample period. Moreover, it ignores the extremely large e-cig excise tax hike that occurred in that state in 2013 (see the next section for details). The study adds two more years to the data used by Cotti, Nesson, and Teft (2018). Unlike Cotti, Nesson, and Teft (2018), Pesko et al. (2019) find that higher cigarette taxes increase adult e-cig use but find no effects of their-cig tax measure.

Abouk et al. (2019) use US birth records 2013 to 2017 to examine the effect of e-cig taxes on pre-pregnancy smoking and prenatal smoking. They find that e-cig taxes increase prepregnancy and prenatal smoking, implying that e-cigs and traditional cigarettes are substitutes among pregnant women. The e-cigarette tax measures are more refined than those in the one by Pesko et al. (2019). Abouk et al. (2019) do not, however, capitalize on the potential evidence contained in the quasi-natural experiment contained in the Minnesota experience and focus on a small segment of the population. ${ }^{7}$

\footnotetext{
${ }_{7}$ Abouk et al. (2019) exclude Minnesota from most of their analysis because it enacted an e-cigarette tax prior to the beginning of their sample year. When they start the study period in 2011 and include Minnesota, the state provides no within-state variation in one of their two wholesale tax measures: the presence of a tax. They do account for the Minnesota tax hike in 2013 (see the next section for details) but assume that Minnesota can be treated in the same manner as the seven other places (the District of
} 
A few studies have conducted randomized control trials (RCT) to test the effectiveness of e-cigs vs. other modes in promoting smoking cessation. Bullen et al. (2013) conducted an RCT that included 657 smokers who wanted to quit. They were randomized into groups which were given e-cigs, placebo e-cigs (without any nicotine), and NRT. The trial lasted for 12 weeks, and the participants were also given limited counseling. Abstinence rates, verified chemically at six months, were $7.3 \%$ for the e-cig are, $4.1 \%$ for the placebo e-cig arm, and $5.8 \%$ for the NRT arm. Thus, e-cigs resulted in a greater likelihood of quitting, and were more effective than both placebo e-cigs and NRT, though the differences were not statistically significant. For those who failed to quit, the median time to relapse was twice as long for participants using e-cigs relative to both placebo e-cigs and NRT. Hajek et al. (2019) conducted an RCT with 886 participants who had sought assistance from the National Health Service in the U.K. to quit smoking. The 1-year abstinence rate was $18.0 \%$ for the e-cig group, as compared with $9.9 \%$ in the nicotine-replacement group. They concluded that e-cigs were more effective for smoking cessation than nicotine replacement therapy, when both products were accompanied with behavioral support. While RCTs can provide more definitive causal evidence, they are limited in their capability of assessing population-level effects under patterns of real-world use and conditions. Furthermore, they do not provide any information on the effects of policies such as e-cig taxation.

Our study provides some of the first evidence of the effects of e-cig taxes on smoking cessation among adults. We also provide the first estimate of the price elasticity of smoking participation with respect to the price of e-cigs implied by the impact of the first imposition of and subsequent large increase in an excise tax on e-cigs in the U.S. in the literature. This estimate is an important input towards evaluating the costs and benefits of e-cig taxation and the harm reduction debate. In the process, we add to the limited literature on how e-cig use is impacting 
adult smokers, drawing on the Minnesota tax hike as a natural experiment to drive exogenous variation in e-cig use.

\section{Approach}

The objective of this study is to provide plausibly causal evidence of the effects of e-cig use on adult smoking. In the empirical work, e-cig taxes serve as a lever that affects e-cig use. E-cig prices are less suitable because of their potentially endogeneity with use. The policy chosen must also have sufficient statistical power to change e-cig use in order to be able to identify downstream effects on smoking. We therefore rely on the large e-cig tax imposed in Minnesota (MN). Nicotine taxes are arguably exogenous to use because they are typically employed by states to raise revenue from products that are seen as harmful and thus face less resistance than taxes on other consumer goods.

MN was the first state to impose a tax on e-cigs by expanding its definition of "tobacco products" to include electronic cigarettes. The taxation began on August $1^{\text {st }} 2010$ (Public Law Health Center) with a tax rate of 35 percent. This tax was raised by another 60 percentage points to a total tax rate of 95 percent of the wholesale price on July $1^{\text {st. }} 2013$. This large tax hike on e-cigs had a substantial impact on prices. Based on retail sales from the Nielsen Scanner Data, e-cig retail prices of replacement pods in 2012 were $\$ 3.25$ in MN (Figure 1). ${ }^{8}$ Dave and Saffer (2013) and studies they cite indicate that tobacco product retailers apply a markup of approximately 1.33 to the wholesale price in setting the retail price. That estimate implies a 2012 wholesale price inclusive of tax of a replacement pod of about $\$ 2.44$ inclusive of tax and exclusive of tax about $\$ 1.80$. The 95 percent tax on $\$ 1.80$ would equal a wholesale price of $\$ 3.52$ and a retail price of $\$ 4.69$. The actual retail price in $M N$ in 2015 was $\$ 4.76$, which suggests that our estimate is a close first-order approximation. ${ }^{9}$

\footnotetext{
${ }^{8} \mathrm{E}$-cig sales in 2010 and 2011 were very limited and consequently the price data for e-cigs in these years may be inaccurate.

${ }^{9}$ We assume that the retail market for e-cigarettes can be characterized by the pure version of the Cournot model of oligopoly (Tirole 1988; Scherer and Ross 1990). Hence the retail price of e-cigarettes
} 
The timing of the MN e-cig tax is also important for our analysis. In 2010 e-cigs were virtually unknown and sales were still relatively low in 2013. A new product needs to be heavily advertised and moderately priced to attract potential consumers. Thus, the MN tax impacted ecigs at a particularly vulnerable time and probably had a greater impact than a similar tax imposed on a mature product. The timing of the MN e-cig tax hike further permits a sufficient time window to be able to observe any changes in smoking rates. A period of two or more years following the tax increase may be necessary because the addictive nature of smoking can lead to dynamics in the consumer response to new incentives and new potential substitutes. In the presence of such lagged effects and given the delay in data availability on smoking, we are necessarily limited to analyzing tax changes that were enacted prior to 2016 . The states that had levied taxes on e-cigs prior to 2016 are North Carolina (6/2015), Louisiana (7/2015) and Minnesota. ${ }^{10}$ The taxes in North Carolina and Louisiana are only five cents per milliliter of eliquid. To put these taxes into perspective, a replacement pod which supplies roughly the nicotine equivalent of a pack of cigarettes cost about $\$ 3.47$ in a state with no tax in 2015 . The five cents per milliliter tax adds about four cents to the retail price which is trivial, leaving the North Carolina and Louisiana taxes under-powered to detect changes in smoking rates and thus empirically irrelevant. After the tax hike in MN in 2013, which raised its total tax rate to 95

is given by $\mathrm{P}=[\varepsilon(/ \varepsilon-h)] \mathrm{C}$, where $\varepsilon$ is the market price elasticity of demand, $\mathrm{h}$ s the Herfindahl index, $\mathrm{C}$ is the sales-share weighted average of each retailer's average cost (assumed to be independent of pods sold) of selling e-cigarettes, and $\varepsilon>h$. Define $m$ as $\varepsilon / \varepsilon-h$; assume that $\varepsilon$ and $h$ are constant; and note that $m>1$. Average cost is given by $C=W^{*}(1+r)+T$, where $W^{*}$ is wholesale price exclusive of tax, $r$ is the wholesale tax rate and $T$ denotes other costs incurred by the retailer per unit of sales. Hence $P=$ $m\left[W^{*}(1+r)+T\right]$. Given these assumptions, the tax pass-through (the increase in $P$ due to an increase in $r$ with $W^{*}$ held constant) exceeds one: $\partial \mathrm{P} / \partial \mathrm{r} \mathrm{W}^{*}=\mathrm{m}$. Let $\mathrm{W}$ be the wholesale price inclusive of tax. Then $\mathrm{P} / \mathrm{W}=\mathrm{k}, \mathrm{k}=\mathrm{m}([1+(\mathrm{mT} / \mathrm{W})]$. We use a value of $\mathrm{k}$ of 1.33 in the computations above. We realize that T/W will change as $\mathrm{W}$ increases due to an increase in $r$, but assume that this effect is small enough to be ignored. Since our estimate of the retail price in Minnesota in 2015 differs from the actual price by only 7 cents, our assumption is very reasonable. Put differently, the tax pass-through to the retail price is approximately 1.33 .

${ }^{10}$ See https://www.publichealthlawcenter.org/sites/default/files/States-with-Laws-Taxing-ECigarettesSeptember152019.pdf. More recently Pennsylvania and California have enacted large e-cig taxes, which can be evaluated as additional waves of data become available. D.C. imposed a tax on e-cigs in late 2015 after the 2015 CPS-TUS data were collected. We limit our data to waves prior to 2018 to draw a sharp contrast between the first state to enact an e-cig tax and all other states and to have a long-enough post period for potential effects to develop. 
percent of the wholesale price, the MN tax remains the highest tax on e-cigs imposed by any U.S. state.

Our aim in this paper is to evaluate the effect of the imposition of a large excise tax on electronic cigarettes by the state of Minnesota on responses by adult smokers ages 18 years and older. We do so by examining its impacts on participation in electronic cigarettes and combustible cigarettes in that state and in a comparison group of states. Few people begin to smoke after that age, causing variations in smoking participation to be governed by decisions to start smoking e-cigarettes and to quit smoking combustible cigarettes. As pointed out above, the imposition of the e-cig excise tax raised the price of e-cigs by a substantial amount. Below we show that the price of e-cigs relative to that of combustible cigarettes also rose in $\mathrm{MN}$, while it fell in the comparison states. Therefore, to get insights into their impacts on smoking participation, we focus on price effects in equations determining the probability of starting to vape and stopping to smoke.

Decisions to start vaping by current vapers depends on a comparison between the money price of vaping and its reservation price. The latter is defined as the monetary value of the marginal utility of vaping, at the point at which no e-cigarettes are purchased. A smoker will not vape if the reservation price is less than the money price, while she will begin to vape if the reverse holds. An increase in the money price will cause some smokers to decide not to begin to vape. Given that consumers who are just at the margin of beginning to vape at the initial price incur fixed costs in the decision-making process, this negative effect can be quite large. These include the cost of the starter kit if a rechargeable device is employed. They also include the need to allocate resources to the acquisition of information about a new product that in part can be characterized as an experience good in the sense that smokers need to try it to decide whether or not they like it. Given the fixed cost, the entry decision also involves comparing the level of utility from two different baskets: one in which no e-cigs are vaped and the other at which a positive number are vaped. There will be one unique relative price at which these two baskets are on the same indifference curve. Hence, the relative price that induces entry must 
be smaller than the one that induces entry in the absence of fixed costs. If there are a large number of consumers with the same utility function, the demand function for starting to vape will be infinitely elastic at the relative price at which this occurs.

Another point to note is that under reasonable assumption about the utility function, vaping is less likely if its effect on the marginal utility of smoking is negative rather than positive. Moreover, the larger in absolute value is this cross-utility effect, the more elastic is the demand function for vaping. Smokers who do not vape at the initial money price are more likely to have a negative cross-utility term than those who do vape. The upshot is that fixed costs combined with negative cross-utility terms are likely to cause a significant number of current smokers to begin to vape and to cause some of them to quit smoking altogether when the price of e-cigs falls. The reverse occurs when the price rises.

For current vapers (dual users of e-cigs and combustible cigs) an increase in its price generates an income effect as well as a substitution effect. The latter involves more smoking and less vaping provided that the two goods are net (utility-constant) substitutes while both smoking and vaping fall if the goods are net complements. The income effect causes the consumption of both to fall provided each one has a positive income elasticity. If they are gross (money income-constant) substitutes, smoking will rise and vaping will fall, while both will fall if they are gross complements.

In summary, this analysis suggests that an increase in the price of vaping will reduce starts and quits and raise smoking participation. This prediction becomes somewhat ambiguous if cigs and e-cigs are gross complements. Moreover, it is possible that the price increase induces some smokers who began to vape because they wanted to quit but were not successful to resort to another method that results in successful quits.

The primary data come from the Current Population Survey Tobacco Use Supplements (CPS-TUS), which are sponsored by the National Cancer Institute and administered periodically as part of the Census Bureau's CPS since 1992. The CPS-TUS offers several advantages for our analyses, including large samples and consistent information on smoking behaviors over 
time, and measures of smoking on the intensive margin. We use eight available waves of the CPS-TUS, which were fielded in 1992-1993, 1995-1996, 1998-1999, 2001-2002, 2003, 20062007, 2010-2011 and 2014-2015. The CPS-TUS is nationally-representative and contains information on about 240,000 individuals within a given wave; it provides a key source of national, state, and sub-state level data regarding smoking and the use of other tobacco products among adults ages 18 and older. This yields a sample of approximately two million adults drawn from repeated cross-sections spanning 1992 to 2015 . We rely on aggregate data at the state-level from each wave, and use smoking participation and cigarette consumption as outcome measures. ${ }^{11}$

The first e-cig tax (35 percent of wholesale price) went into effect in August 2010 in MN, and the subsequent tax hike (to 95 percent) went into effect in July 2013 . We consider all waves up to 2010-2011 as the pre-treatment periods. Given that the prevalence of e-cig use in 2010 and 2011 remained quite low (less than 1 percent; see Dave et al. 2019) and given that it may take some time to change smoking habits, any effect of the e-cig tax in 2010 is unlikely to materialize until after 2010. In addition, the 2010-2011 TUS was conducted in May, 2010, August 2010, and January 2011. Data from the 2014-2015 wave of the CPS-TUS are considered the post-treatment period, allowing us to observe any potential effects on adult smokers that may have materialized 2-3 years post MN's e-cig tax.

We employ a difference-in-differences (DD) model to estimate how the e-cig tax hike in MN impacted adult smoking behaviors. The key assumption necessary for the DD estimate to signify an unbiased causal effect is that the control group of states represents a valid counterfactual for $\mathrm{MN}$ in the absence of the e-cig tax. Figure 4 plots the trend in the smoking rate in MN and the rest of the U.S. (excluding MA and IL as they substantially increased their cigarette excise in the post-treatment period). Smoking rates in MN and the rest of the U.S., while trending downward over the past two decades, do not appear to be doing so in a lockstep

\footnotetext{
11 More information on the CPS-TUS can be found at: https://cancercontrol.cancer.gov/brp/tcrb/tuscps/questionnaires.html.
} 
parallel manner. Particularly, the difference in the pre-treatment smoking rate between the two groups is widening over most of the 1990s, then narrows until about 2007, before widening again. Hence, the rest of the U.S. may not be a good counterfactual for what would have happened in MN in the absence of the e-cig tax. Since any downstream effects from e-cig taxes to e-cig use to smoking cessation may be small, they risk being confounded from even relatively small deviations from pre-treatment parallel trends.

We therefore undertake a synthetic control design, following Abadie, Diamond, and Hainmueller (2010), to ensure that the treatment (MN) and control states share common pretreatment trends in adult smoking outcomes. The algorithm underlying this method assigns weights to each donor state so that any pre-treatment differences in outcomes between $\mathrm{MN}$ and the synthetically matched "state" (SMN) are minimized. Hence, by expressly forcing the e-cig tax counterfactuals to have more similar pre-treatment trends, a synthetic control DD design raises the likelihood of satisfying the "parallel trends" assumption. ${ }^{12}$

One challenge in this framework relates to the computation of the correct standard errors, given that there is only a single treatment group and a single control group. Donald and Lang (2007) show that standard significance tests cannot be applied in this case. They refer to Moulton (1990) who shows that in regression models with individual data, the failure to account for the presence of common group errors results in standard errors that are biased downward and consequently overstate significance levels. Clustering the standard errors is not an option with only two groups or clusters. We follow the approach in Donald and Lang (2007), who suggest first computing group means to eliminate the common group error and then computing the difference between the treatment and control group for each period. We then estimate a regression of these differences on an indicator for the post-tax period.

The standard errors may still need to be adjusted for serial correlation of the group difference over time, which can be done by taking adjacent period differences in the outcome

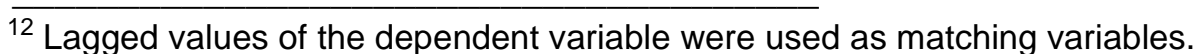


difference between the treated and control groups for each period. This adjustment for serial correlation proposed by Donald and Lang (2007) assumes that the disturbance term follows a random walk. It also assumes time spacing between the data points, which is not the case with the CPS-TUS waves. One option is to drop the 2001-2002 wave, which creates a time series with two three-year gaps and four four-year gaps. In this case, the correlation in the error terms across three-year intervals and four-year intervals is assumed to be approximately similar. We refer to these data as Wave Differences in the presentation of the results and tables.

Changes in cigarette prices during the post-treatment period are relevant because they can affect smoking rates in the potential donor pool and in $\mathrm{MN}$ outside of any effects due to the e-cig tax. The post-treatment period spans 2011 through mid-2015 as the TUS in 2015 was last collected in May. Minnesota increased its cigarette excise tax by $\$ 1.60$ to $\$ 2.83$ in July 2013 and by another $\$ 0.07$ in January 2015 . Massachusetts and Illinois both increased their cigarette excise tax by $\$ 1.00$ during the post-treatment period and were therefore dropped from the pool of potential donor states. They were the only states other than $\mathrm{MN}$ that enacted large cigarette tax hikes during this period. The range of small cigarette tax increases in the included states during the post-period is from $\$ 0.10$ in New Hampshire to $\$ 0.40$ in Connecticut.

To understand the effects of these tax changes on e-cig prices and cigarette prices, trends in both and in the relative price are presented in Figures 1-3 for MN and its synthetic control. ${ }^{13}$ Price measures from the Nielsen Retail Scanner data indicate that the average price of a pack of cigarettes in MN in 2011 was $\$ 5.41$ and fairly similar at $\$ 5.89$ in the synthetic control group (SMN). By 2015 these prices had increase in MN to $\$ 7.83$ and $\$ 6.07$ in SMN (Figure 2). Figure 3 shows the relative price of e-cigs versus cigarettes in MN and SMN. In 2012, relative prices for both MN and the control group were virtually the same, 0.55 and 0.56 respectively. By 2015, following the tax increase, the relative price in $\mathrm{MN}$ had risen to 0.61 and

\footnotetext{
${ }^{13}$ SMN is the synthetic control group formed by applying the synthetic weights generated from the smoking participation model. We do not generate new weights specifically for matching prices, since we want to analyze the tax pass-through and effects of the tax on prices based on the same control group for which we analyze smoking outcomes.
} 
fallen in SMN to 0.52. That is, in MN the price of e-cigs rose by 17 percent relative to cigarettes, when compared to SMN.

As predicted by the theory, this increase in the relative price of vaping would lead to a decrease in participation and use of e-cigs. Given the lack of information on e-cig consumption in the pre-treatment period, we focus on what happens to smoking participation. Our focus on cigarette use is also salient in that it directly addresses the harm reduction debate surrounding adult smokers. The increase in the price of e-cigs, and in the relative price of e-cigs is predicted to increase smoking rates given that smoking and vaping are substitutes. This conclusion depends on the relationship between e-cigs and cigarettes and is ultimately an empirical question.

\section{Results}

As a point of comparison, we start by presenting standard DD estimates utilizing the rest of the U.S. (excluding MN, and MA and IL) as a control group, in Table 1. An alternate specification, following Donald and Lang (2007), is estimated to generate appropriate standard errors that adjust for within-group correlated errors when there is only a single treatment and control group. The model denoted DL1 is based on the difference in the aggregated outcome across the treated group (MN) and the control group, which adjust for within-group and year correlated errors. The model denoted DL2 further corrects for serial correlation (thus adjusting for any correlated errors over time) by further differencing the DL1 data across adjacent waves. These estimates do not indicate any significant effects of the large e-cig tax in MN on smoking rates. The effects however may be biased due to differential pre-treatment trends between MN and the rest of the U.S. (Figure 4), and we therefore rely on the synthetic control approach to generate a more suitable counterfactual for $\mathrm{MN}$.

Tables 2-4 present estimates from synthetic control DD models for three smoking outcomes. In Table 2, we report estimates of the effects on current smoking prevalence, which is the percentage of adults who reported ever smoking at least 100 cigarettes and who currently 
smoke every day or some days. The corresponding event study graph comparing MN with synthetic MN is in Figure 5. It is evident from the figure that the control group here matches MN virtually lockstep with respect to changes in the smoking rate in all of the pre-treatment periods, with a divergence observed only after the imposition of the large e-cig tax. Estimates in Table 2 confirm the graphical evidence that the e-cig tax in MN is associated with a significant increase in the prevalence of smoking among adults. Estimates from the first two specifications indicate an increase in smoking prevalence by almost one percentage point (0.8 to 0.9 percentage points), representing about a 5.4 percent increase relative to the immediate pre-treatment mean in MN. Ideally the time-differenced data used in the DL2 model should be based on the same spacing between adjacent periods. However, given the staggered nature of the CPS-TUS surveys, the spacing is somewhat uneven. ${ }^{14}$

We alternately tested for statistical significance based on a permutation of placebo tests, in the spirit of Abadie, Diamond and Hainmueller (2010) as modified by Bedard and Kuhn (2012) and Stearns (2015). This placebo test alternatively assumes that each state is the treatment state and finds a synthetic control group for that placebo. Then we estimate the DL2 specification for all placebo states. This provides a p-value for the treatment effect for each placebo state, generating a distribution of p-values. Finally, we compare the actual treatment state's (MN) position in this distribution of p-values in order to gauge whether the results could be generated due to chance. For example, if 49 states are used and MN has the highest $p$ value of all states, then the test statistic would be $1 / 49=0.02$. This would be interpreted as a 2 percent probability that the outcome for $\mathrm{MN}$ was due to chance. This placebo $\mathrm{p}$-value is presented in the graphs for each outcome.

For the model for current smoking prevalence, the placebo test found that MN had the second smallest p-value out of 49 states, implying about a 4 percent probability of a Type 1 error. Figure 5 and the treatment effects in Table 2 show that smoking increased in MN relative

\footnotetext{
14 Note that a relatively large t-statistic is needed to achieve statistical significance due to the small sample sizes with group-period aggregated data.
} 
to the control group following the e-cigarette tax. Because the relative price of e-cigs increased in MN compared to SMN (Figure 3), these results imply that cigarettes and e-cigs are substitutes among current smokers.

For adults, any changes in smoking prevalence are very unlikely to reflect the initiation margin (given that most current smokers have initiated by age 19 or 20). Changes in smoking prevalence then reflects mostly the cessation margin or possibly the relapse margin from former to current smoking. In Figure 6, with corresponding DD estimates in Table 3, we report effects on smoking cessation, by defining the ratio of the number of individuals who smoked but recently quit (former smokers) divided by the number of ever smokers. Trends in this outcome are virtually identical between $\mathrm{MN}$ and the control group. The placebo test indicated that $\mathrm{MN}$ had the third smallest $p$-value out of 49 iterative state tests, implying about a $6 \%$ probability of a Type I error. Estimates in Table 3 indicate that the e-cig tax in MN led to a decrease in quitting by about 1.14 percentage points, which is the same order of magnitude as in the models for smoking prevalence. This suggests that virtually all of the increase in current smoking prevalence in $\mathrm{MN}$, associated with the e-cig tax, is driven by a decrease in successful quits.

Finally, we also consider whether the e-cig tax led to any changes in cigarette consumption at the intensive margin. That is, even if smokers in MN may not have quit, did they reduce their consumption of combustible cigarettes? Cigarettes per day may decline, for instance, as smokers may be trying to cut down as a progressive step toward cessation. Figure 7, and the corresponding estimates in Table 4, indicate that this is not the case. Cigarettes per day are not reported for 2003 and thus, for this variable, the 2002 data are used. We do not find any significant change in the number of cigarettes consumed among current everyday smokers in $\mathrm{MN}$ relative to the control group following the e-cig tax.

As a robustness check, we also tested data on current smoking prevalence from the Behavioral Risk Factor Surveillance System (BRFSS). The BRFSS is a cross-sectional telephone survey that state health departments conduct by phone with a standardized questionnaire and technical assistance from CDC. The BRFSS is based on between 355,000 to 
506,000 interviews each year between 2006 and 2017. The sample period begins in 2006 because in that year the CDC introduced a new weighting method to insure a representative sample at the state level. Another issue with the BRFSS is that it changed its survey design in 2011, which is also the first period of the treatment. The 2011 BRFSS data reflects a change in weighting methodology and the addition of cell phone only respondents. This change is evident in figure 8 as a jump in the smoking rate in 2011. However, because this change affected all states it should not lead to any systematic differential between MN and the control states. Again, MA and IL are dropped from the control pool because of large increases in the cigarette tax in the post-period. Figure 8 presents the graph comparing $\mathrm{MN}$ and its synthetic control group from the BRFSS. While the smoking rates in the BRFSS are noisier than those in the TUS, pre-treatment trends are well-balanced between the treatment and the control. There is a small apparent effect in 2011 which was not seen in the TUS data. The reason for this is likely because the 2011 TUS data is for $2010-2011$ and primarily reflects 2010 . The BRFSS effect size gets larger with the exception of 2013, which might be due to a transitory effect of the 2013 cigarette tax increase in MN. The placebo test resulted in a value of $p<.13$.

The DL1 results in table 5 suggest that smoking prevalence increased in $\mathrm{MN}$ following the e-cig tax relative to the control group. Effect magnitude for the entire post period is similar to the effect estimated from the TUS and suggests an increase in smoking prevalence of about 1 percentage point. The serial correlation adjustment used in DL2 is not useful with the BRFSS data because it measures only the effect in the first post period rather than the average effect over the entire post period (see the second regression in table 5). As an alternative we specify a model with lagged effects of the e-cig tax for each post-policy period, which is a post period event history study. All the post dummies are equal to 0 in 2006-2010. Then, post $0=1$ in 2011 and equals 0 in all other post years. Post1 = 0 in 2011, equals 1 in 2012 and 0 in all other post years, etc. This is a model in level form. We then define the time difference specification to account for serial correlation. This regression provides the correct standard errors and 95 percent confidence intervals for each of the 7 post-year differences. These data are presented 
in figure 9. The average effect over the seven years is 1.0084 with a standard error $=0.5488$ and $p$-value $<0.14$. This average value is slightly smaller than the value of 1.0404 in the level model (DL1). Also, the confidence intervals for all post periods includes the numeric value 1. Confidence in the conclusions are enhanced because both the BRFSS models and the TUS models predict about a 1 percentage point increase in smoking participation due to the tax.

\section{Conclusions}

The results presented in this study provide some of the first evidence on whether, and the extent to which, e-cig taxation affect adult smoking behaviors. We exploit the natural experiment provided by MN, the first state to impose a tax on e-cigs. Because the cross effects of a tax on e-cigs on smoking outcomes may be small, a large tax change is necessary to reliably detect such effects in population surveys. Also, because quitting smoking takes time, MN's early adoption of the large e-cig tax makes it possible to study effects on cessation that may take time to materialize. We find consistent and robust evidence that the e-cig tax in MN increased adult smoking relative to what it would have been in the absence of this tax. MN included e-cigs with other non-cigarette tobacco products when increasing the tax on these goods. This inclusion was based on the assumption that e-cigs are a hazard and not a cessation aid such as nicotine replacement products, which are not similarly taxed. It is not known at this time whether these results are generalizable to other states. Higher e-cig taxes are predicted to reduce e-cig consumption, and if the results from MN carry over to other states that have imposed taxes very recently, then they suggest that these taxes will also reduce quit rates in these states among adult smokers.

The results from the TUS and the BRFSS allow us to estimate the cross-price elasticity of current smoking participation with respect to e-cig prices. The e-cig price data prior to 2012 is based on a limited sample of observations, which may introduce bias. Thus, we estimate the changes in price using data from 2012 onward. As shown in figure 1, the price of e-cigs in MN and SMN were about the same in 2012. The e-cig tax increase of 60 percent (change from 35 
percent to 95 percent) of the wholesale price in 2013 led to about a 50 percent increase in the price of e-cigs in MN in 2015 relative to the synthetic control. Given the large percentage increase in price, we estimate the arc price elasticity, which allows for the possibility that the elasticity may not be constant over the entire range of the smoking participation equation. The DD estimates indicate that this change is associated with about a 0.8 percentage point increase in current smoking prevalence, which is about a 5.4 percent increase in $\mathrm{MN}$ relative to its control. Division of the increase in price of $\$ 1.61$ by the average of the SMN and MN price in 2015 of $\$ 3.96$ yields a 40.7 percent increase in price and an arc cross-price elasticity of 0.13 . This estimate is a lower bound because the simultaneous increase in cigarette prices would have decreased smoking. ${ }^{15}$ It is notable that the much more modest 17 percent increase in the relative price of e-cigarettes was accompanied by an approximate 5 percent increase in smoking participation. That suggests that if states raise cigarette and e-cigarette taxes by substantial amounts at the same time, smoking will rise if the relative price of e-cigarettes rises.

In 2014 there were about 600,000 adult smokers in Minnesota. Our estimates indicate that the e-cig tax deterred about 32,400 adult smokers from quitting. Currently there are approximately 34 million adult smokers. If the Minnesota tax had been a national one, we estimate that it would have deterred around 1.83 million smokers from quitting. ${ }^{16}$ Some have suggested that e-cigs should be taxed at the same rate as cigarettes. Implementation of that policy would raise the price of e-cigs by approximately 62 percent, increase smoking participation by 8.1 percent, and deter approximately 2.75 million smokers from quitting. ${ }^{17}$

\footnotetext{
15 The simultaneous increase in other non-cigarette tobacco prices would probably have had a small positive effect on cigarette smoking offsetting some of the effects of higher cigarette taxes.

16 This figure is obtained by multiplying 600,000 by the percentage increase in smoking participation divided by $100(600,000 \times 0.054=32,400)$. If MN data apply to the entire US, $0.054 \times 34$ million $=1.83$ million.

${ }^{17} \mathrm{~A}$ JUUL pod contains the nicotine equivalent of a pack of cigarettes and costs about $\$ 4.00$. The combined federal cigarette tax and state average cigarette tax is $\$ 2.73$ per pack. A tax of $\$ 2.73$ with a pass-through of 1.33 (see note 8) would raise the price by of e-cigs by $\$ 3.63$, which is an increase of 62 percent relative to an average of the initial and the final price. Divide that figure by 100 and then multiply the result by the arc cross-price elasticity of 0.13 to get an increase in smoking participation of 0.081 or 8.1 percent. Multiplication of the former number by 34 million gives 2.75 million.
} 
While these increases may appear to be large, they are likely to be realized over a period as long as a decade. That is the short-run impact of the price hikes are likely to be much smaller than the long-run impacts. To put this in a somewhat different perspective, a projection of current trends in the number of smokers who quit over the next decade suggests that around 11 million smokers will quit by the end of that decade. ${ }^{18}$ Our computations imply a reduction in that number by around 25 percent.

Our study addresses how e-cig use impacts adult smoking, which represents one side of the policy debate surrounding e-cigs. For adolescents, nicotine addiction, the potential progression from vaping to smoking, and the growing percentage of using e-cigs are also important considerations in this policy debate. E-cigs are considered to be harmful to youth due to the effect of nicotine on the developing brain and due to the potential for vaping to lead to nicotine addiction (regardless of whether or not the youth transitions to smoking). While the results from this study indicate that e-cigs may help adult smokers to quit smoking and thus lead to a decrease in smoking-related harms, this needs to be balanced against the goal of reducing vaping and nicotine use among youth. Deterrents to adolescent use include raising the national minimum purchase age to 21 , allocating resources to enforcing that law, enacting stiff fines for violating it, and banning flavors and marketing targeted at youth. The public health benefits of not taxing e-cigarettes must be weighed against effects of this decision on efforts to reduce vaping by youth.

${ }_{18}$ Currently, approximately 1.3 million smokers quit each year, which implies a quit rate of 0.038 (3.8 percent). If there are no starters or relapsers, there would be $(0.962)^{10} \times 34$ million $=23$ million remaining smokers ten years hence and 11 million quitters over that period. If the net percentage reduction in the number of smokers is less than 3.8 percent, we overestimate the number quitters. 


\section{References}

Abouk, Rahi Scott Adams, Bo Feng, Johanna Catherine Maclean, Michael F. Pesko. 2019.

"The Effect of E-Cigarette Taxes on Pre-Pregnancy and Prenatal Smoking, and Birth

Outcomes." National Bureau of Economic Research Working Paper No. 26126, July.

Abadie, Alberto, Alexis Diamond, and Jens Hainmueller. 2010. "Synthetic Control Methods for Comparative Case Studies: Estimating the Effect of California's Tobacco Control Program." Journal of the American Statistical Association 105(490): 493-505.

Babb, Stephen, Ann Malarcher, Gillian Schauer, Kat Asman, and Ahmed Jamal. 2017. "Quitting Smoking Among Adults — United States, 2000-2015." MMWR Morb Mortal Wkly Rep 65(52): 1457-1464. DOI: http://dx.doi.org/10.15585/mmwr.mm6552a1external icon

Bedard, Kelly, and Peter Kuhn. 2015. "Micro-marketing Healthier Choices: Effects of Personalized Ordering Suggestions on Restaurant Purchases." Journal of Health Economics 39: 106-122.

Bullen, Christopher, Colin Howe, Murray Laugesen, Hayden McRobbie, Varsha Parag, Jonathan Williman, and Natalie Walker. 2013. "Electronic Cigarettes for Smoking Cessation: A Randomised Controlled Trial." The Lancet 382(9905): 1629-1637.

Brown, Jamie, Emma Beard, Daniel Kotz, Susan Michie, and Robert West. 2014. "Real-world Effectiveness of E-cigarettes When Used to Aid Smoking Cessation: A Cross-sectional Population Study." Addiction 109(9): 1531-1540.

Campaign for Tobacco-Free Kids. 2019. "State Excise Tax Rates for Non-Cigarette Tobacco Products." https://www.tobaccofreekids.org/assets/factsheets/0169.pdf, last accessed December 10.

Cawley, John, and Christopher J. Ruhm. 2012. "The Economics of Risky Behaviors." In Handbook of Health Economics, Volume 2, edited by Mark V. Pauly, Thomas G. McGuire, and Pedro Pita Barros. Amsterdam: North-Holland, Elsevier Science: 95-199.

Chaiton, Michael, Lori Diemert, Joanna E. Cohen, Susan J. Bondy, Peter Selby, Anne Philipneri, and Robert Schwartz. 2016. "Estimating the Number of Quit Attempts It Takes to Quit Smoking Successfully in a Longitudinal Cohort of Smokers. BMJ open 6(6): e011045.

Cotti, Chad, Erik Nesson, and Nathan Tefft. 2018. "The Relationship between Cigarettes and Electronic Cigarettes: Evidence from Household Panel Data." Journal of Health Economics 61(C): 205-219.

Czogala, Jan, Maciej L. Goniewicz, Bartlomiej Fidelus, Wioleta Zielinska-Danch, Mark J. Travers, and Andrzej Sobczak. 2014. "Secondhand Exposure to Vapors from Electronic Cigarettes." Nicotine \& Tobacco Research 16(6): 655-662.

Dave, Dhaval, and Henry Saffer. 2013. "Demand for Smokeless Tobacco: Role of Advertising." Journal of Health Economics 32(4): 682-697.

Dave, Dhaval, Daniel Dench, Michael Grossman, Donald S. Kenkel, and Henry Saffer. 2019. "Does E-cigarette Advertising Encourage Adult Smokers to Quit?" Journal of Health Economics 68(December). https://doi.org/j.jhealeco.2019.10227. 
Donald, Stephen G., and Kevin Lang. 2007. "Inference with Difference-in-differences and Other Panel Data." The Review of Economics and Statistics 89(2): 221-233.

Goniewicz, Maciej Lukasz, Jakub Knysak, Michael Gawron, Leon Kosmider, Andrzej Sobczak, Jolanta Kurek, Adam Prokopowicz, Magdalena Jablonska-Czapla, Czeslawa Rosik-Dulewska, Christopher Havel, Peyton Jacob, 3rd, and Neal Benowitz. 2013. "Levels of Selected Carcinogens and Toxicants in Vapour from Electronic Cigarettes." Tobacco Control 23(2): 1339.

Grana, Rachel, Neal Benowitz, and Stanton A. Glantz. 2014. “E-cigs." Circulation 129(19): 1972-1986.

Hajek, Peter, Anna Phillips-Waller, Dunja Przulj, Francesca Pesola, Katie Myers Smith, Natalie Bisal, Jinshuo Li et al. 2019. "A Randomized Trial of E-cigs Versus Nicotine-replacement Therapy." New England Journal of Medicine 380(7): 629-637.

Huang, Jidong, John Tauras, and Frank J. Chaloupka. 2014. "The Impact of Price and Control Policies on the Demand for Electronic Nicotine Delivery Systems." Tobacco Control 23(suppl 3): iii41-iii47.

Kalkhoran, Sara, and Stanton A. Glantz. 2016. "E-cigs and Smoking Cessation in Real-world and Clinical Settings: A Systematic Review and Meta-analysis." The Lancet Respiratory Medicine 4(2): 116-128.

McNeill, Ann, Leonie S. Brose, Robert Calder, Sara C. Hitchman, Peter Hajek, and Hayden McRobbie. 2015. "E-cigs: An Evidence Update." A report commissioned by Public Health England. Public Health England, 111.

Moulton, Brent R. 1990. "An Illustration of a Pitfall in Estimating the Effects of Aggregate Variables in Micro Units." The Review of Economics and Statistics 72(2): 334-338.

New York Times. https://www.nytimes.com/2019/09/25/health/juulvaping.html?searchResultPosition=1.

Pesko, Michael F., Charles J. Courtemanche, and Johanna Catherine Maclean. 2019. "The Effects of Traditional Cigarette and E-Cigarette Taxes on Adult Tobacco Product Use." National Bureau of Economic Research Working Paper No. w26017.

Public Law Health Center. https://www.publichealthlawcenter.org/sites/default/files/States-withLaws-Taxing-ECigarettes-June152019.pdf.

Scherer, F.M. and David Ross. 1990. Industrial Market Structure and Economic Performance, 3rd Ed. Boston: Houghton Mifflin Company,

Stearns, Jenna. 2015. "The Effects of Paid Maternity Leave: Evidence from Temporary Disability Insurance." Journal of Health Economics 43(September): 85-102.

Tirole, Jean. 1988. The Theory of Industrial Organization. Cambridge, MA: MIT Press.

Tuchman, Anna E. 2019. "Advertising and Demand for Addictive Goods: The Effects of Ecigarette Advertising." Marketing Science 38(6): 913-1084, ii-ii913. 
Weaver, Scott R., Jidong Huang, Terry F. Pechacek, John Wesley Heath, David L. Ashley, and Michael P. Eriksen. 2018. "Are Electronic Nicotine Delivery Systems Helping Cigarette Smokers Quit? Evidence from a Prospective Cohort Study of US Adult Smokers, 20152016." PloS One 13(7): e0198047.

Zheng, Yuqing, Chen Zhen, James M. Nonnemaker, and Daniel Dench. 2016. "Advertising, Habit Formation, and U.S. Tobacco Product Demand." American Journal of Agricultural Economics 98(4): 1038-1054.

Zheng, Yuqing, Chen Zhen, Daniel Dench, and James M. Nonnemaker. 2017. "U.S. Demand for Tobacco Products in a System Framework." Health Economics 26(8): 1067-1086.

Zhu, Shu-Hong, Yue-Lin Zhuang, Shiushing Wong, Sharon E. Cummins, and Gary J. Tedeschi. 2017. "E-cig Use and Associated Changes in Population Smoking Cessation: Evidence from US Current Population Surveys." BMJ 358: j3262.

Zhuang, Yue-Lin, Sharon E. Cummins, Jessica Y. Sun, and Shu-Hong Zhu. 2016. "Long-term E-cig Use and Smoking Cessation: A Longitudinal Study with US Population." Tobacco Control 25(Suppl 1): i90-i95. 


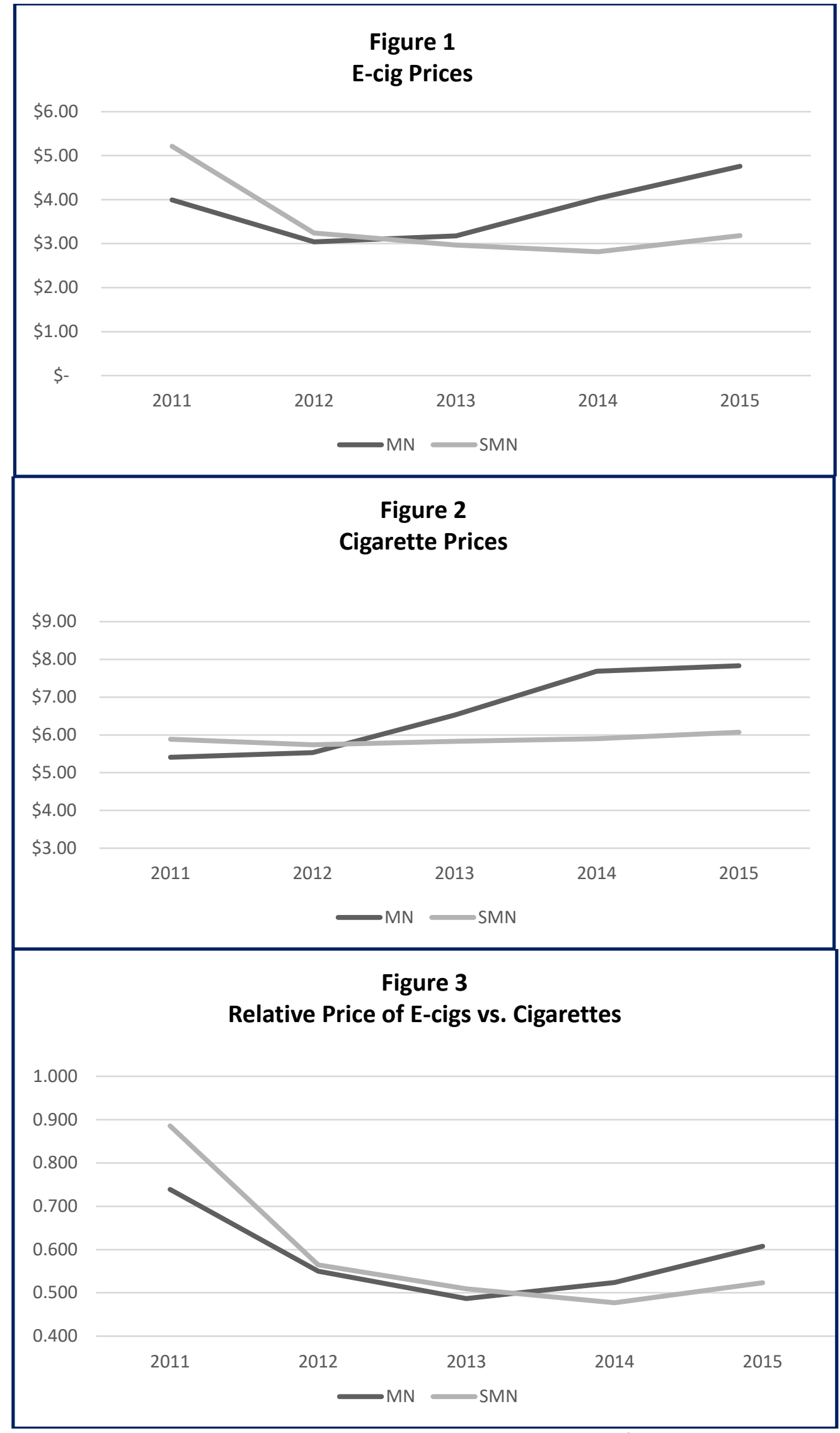

Note: Price computations are based on the Nielsen Scanner Data for MN and synthetic MN. 


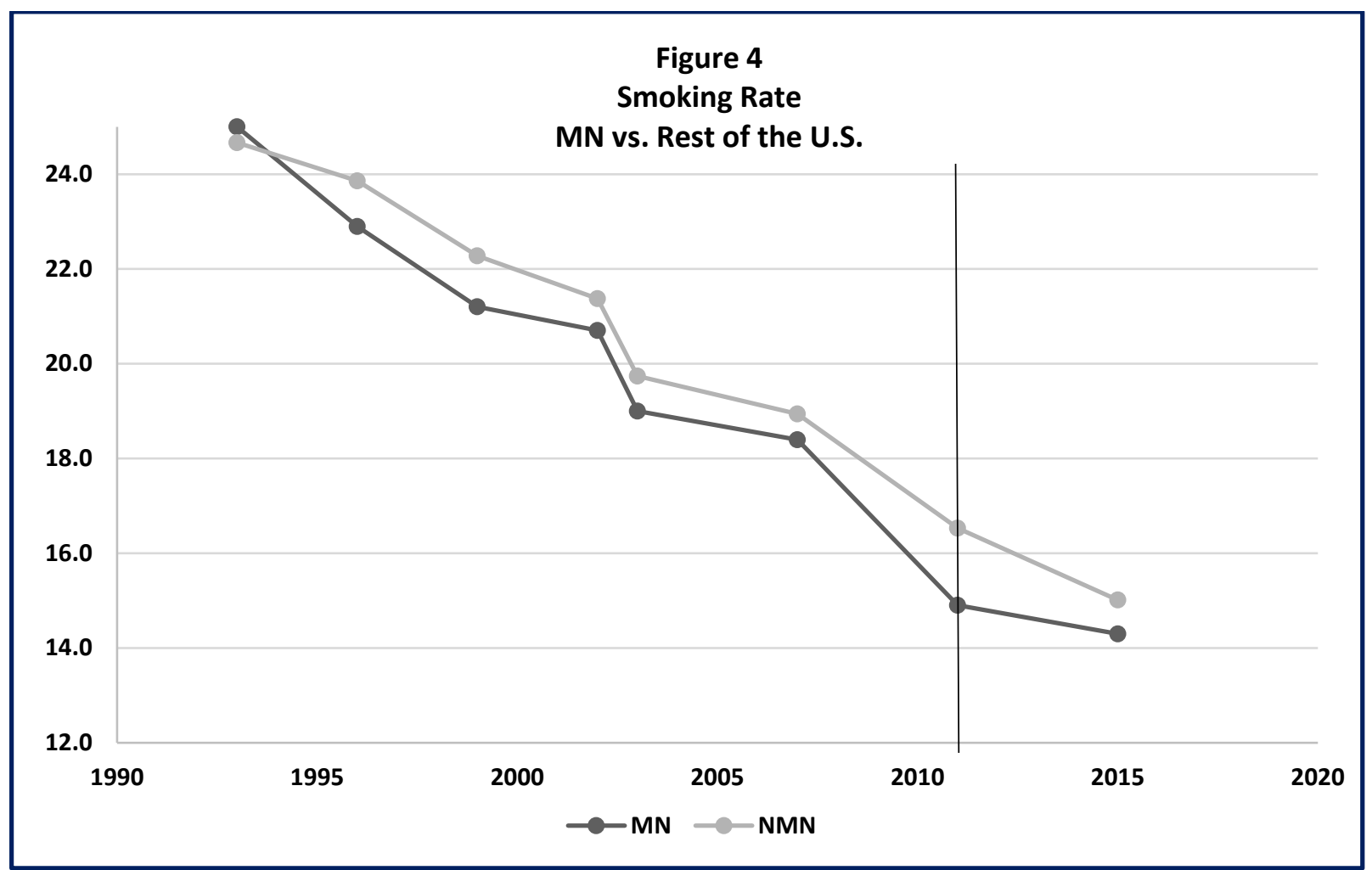

Note: $\quad$ NMN is the population-weighted average smoking rate for the rest of the U.S. excluding MN. IL and MA are excluded from the rest of the U.S. (see text).

\begin{tabular}{|c|l|c|c|c|c|}
\hline \multicolumn{7}{|c|}{$\begin{array}{c}\text { Table 1 } \\
\text { Donald and Lang Models of the Smoking Rate } \\
\text { DD: MN vs. Rest of the U.S. }\end{array}$} \\
\hline Model type & \multicolumn{1}{|c|}{ Data } & $\begin{array}{c}\text { Treatment } \\
\text { Effect }\end{array}$ & $\begin{array}{c}\text { Standard } \\
\text { Error }\end{array}$ & t-value & P-value \\
\hline DL1 & Levels & -0.0289 & 0.6416 & -0.04 & 0.966 \\
\hline DL2 & Wave Differences & 0.9200 & 0.6320 & 1.46 & 0.196 \\
\hline
\end{tabular}




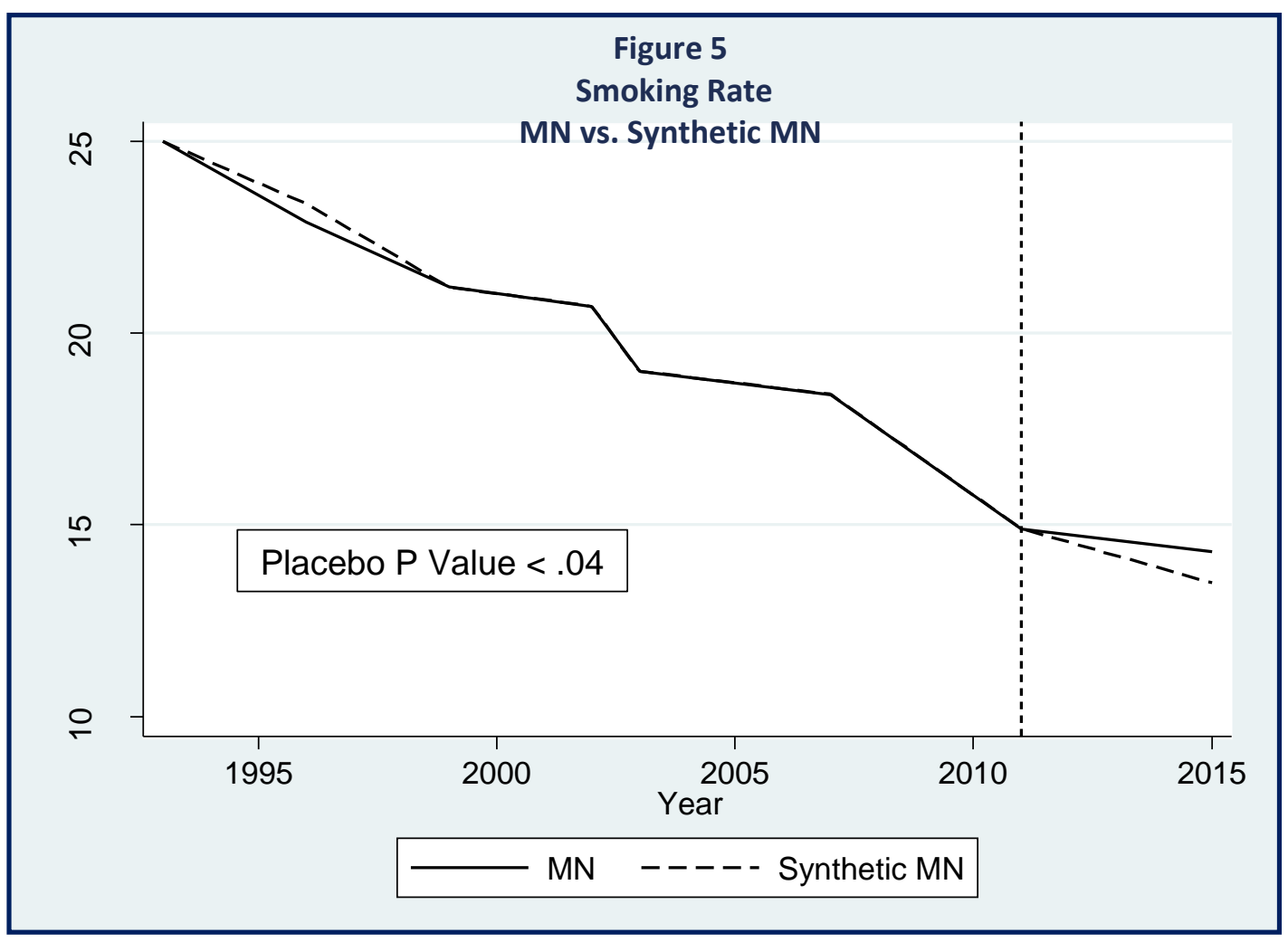

\begin{tabular}{|c|l|c|c|c|c|}
\hline \multicolumn{7}{|c|}{$\begin{array}{c}\text { Table 2 } \\
\text { Effect of the MN E-cigarette Tax on Smoking } \\
\text { DD: MN vs. Synthetic MN }\end{array}$} \\
\hline Model type & \multicolumn{1}{|c|}{ Data } & $\begin{array}{c}\text { Coefficient of } \\
\text { the treatment } \\
\text { variable }\end{array}$ & $\begin{array}{c}\text { Standard } \\
\text { Error }\end{array}$ & t-value & P-value \\
\hline DL1 & Levels & $0.9264^{\star * *}$ & 0.2094 & 4.42 & 0.004 \\
\hline DL2 & Wave Differences & $0.8449^{\star \star}$ & 0.3250 & 2.60 & 0.048 \\
\hline
\end{tabular}

Note: 2002 data are not used in the model for Wave Differences. Asterisks denote significance as follows: ${ }^{* * *} p$-value $\leq 0.01,{ }^{* *} 0.01<p$-value $\leq 0.05,{ }^{*} 0.05<p$-value $\leq 0.10$. 


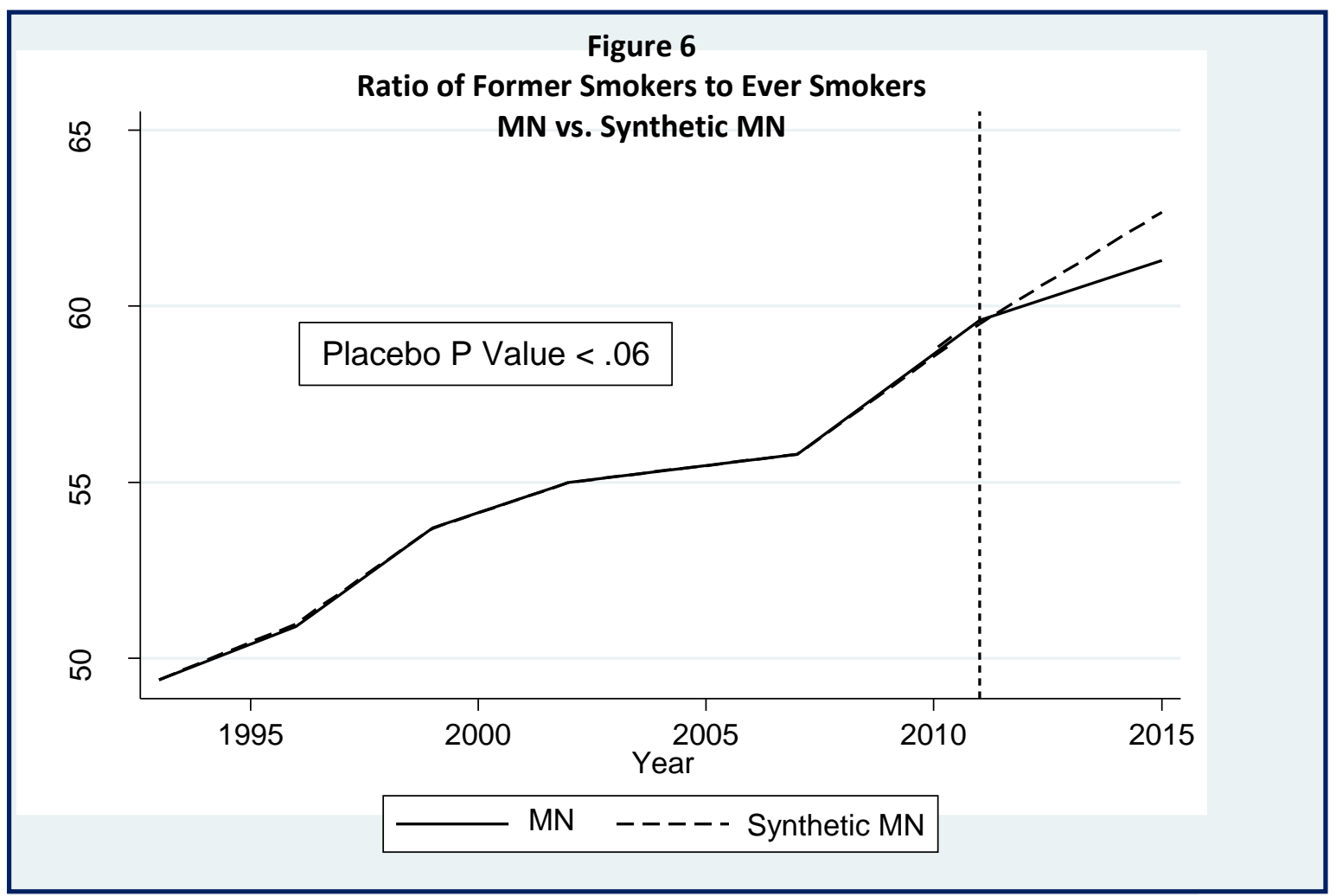

Table 3

Effect of the MN E-cigarette Tax on Ratio of Former Smokers DD: MN vs. Synthetic MN

\begin{tabular}{|c|l|c|c|c|c|}
\hline Model type & \multicolumn{1}{|c|}{ Data } & $\begin{array}{c}\text { Coefficient of } \\
\text { the treatment } \\
\text { variable }\end{array}$ & $\begin{array}{c}\text { Standard } \\
\text { Error }\end{array}$ & t-value & P-value \\
\hline DL1 & Levels & $-0.9526^{\star \star *}$ & 0.1870 & 5.09 & 0.002 \\
\hline DL2 & Wave Differences & $-1.2326^{\star \star *}$ & 0.2425 & 5.08 & 0.004 \\
\hline
\end{tabular}

Note: 2002 data are not used in the model for Wave Differences. Asterisks denote significance as follows: ${ }^{* \star *} p$-value $\leq 0.01,{ }^{* *} 0.01<p$-value $\leq 0.05,{ }^{*} 0.05<p$-value $\leq 0.10$. 


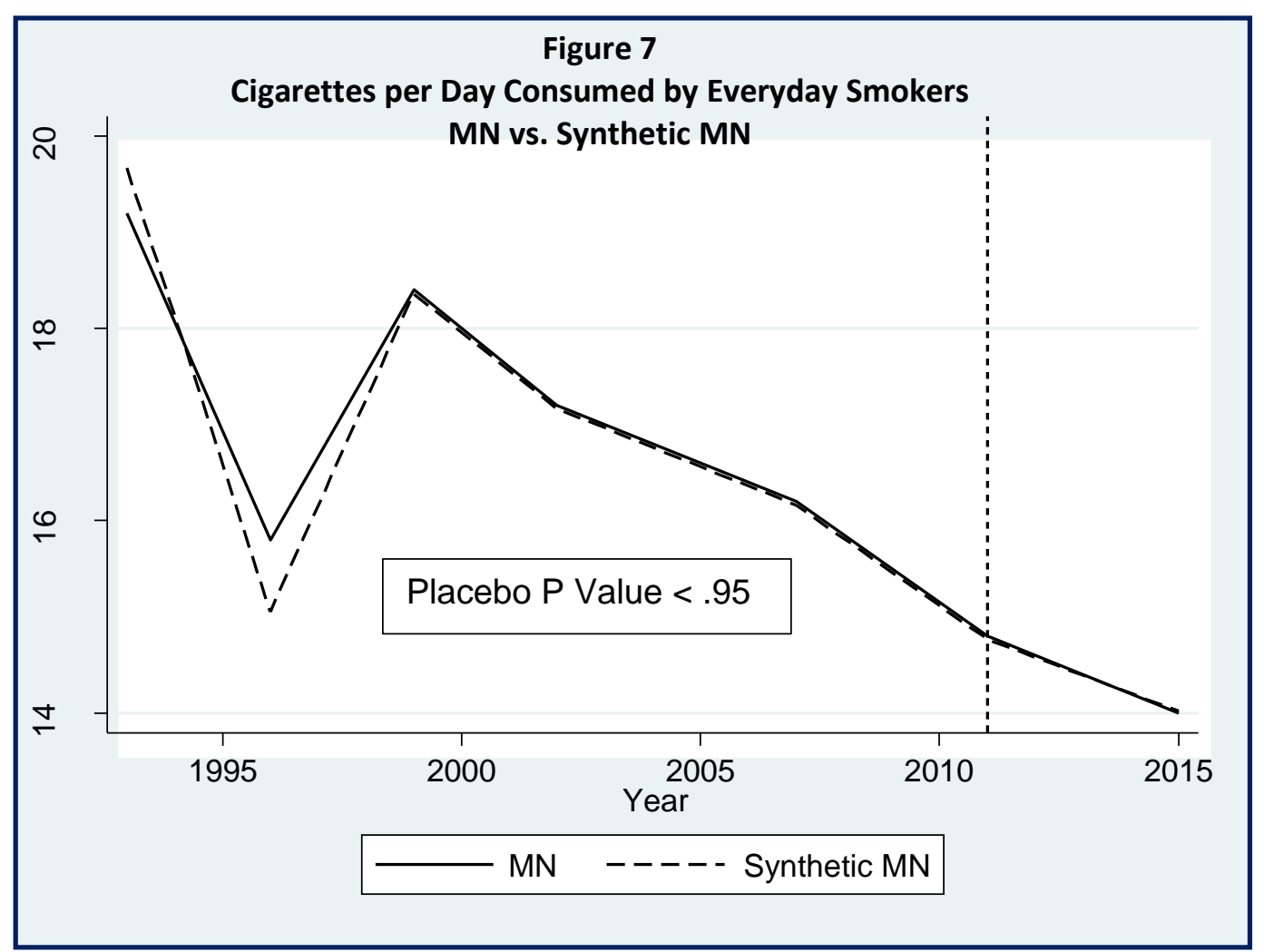

\begin{tabular}{|c|l|c|c|c|c|}
\hline \multicolumn{6}{|c|}{ Table 4 } \\
Effect of the MN E-cigarette Tax on Daily Cigarette Consumption (Intensive Margin) \\
DD: MN vs. Synthetic MN
\end{tabular}

Note: Data on cigarettes consumed are not available for 2003. Asterisks denote significance as follows: ${ }^{* *} p$-value $\leq 0.01,{ }^{* *} 0.01<p$-value $\leq 0.05,{ }^{*} 0.05<p$-value $\leq 0.10$. 


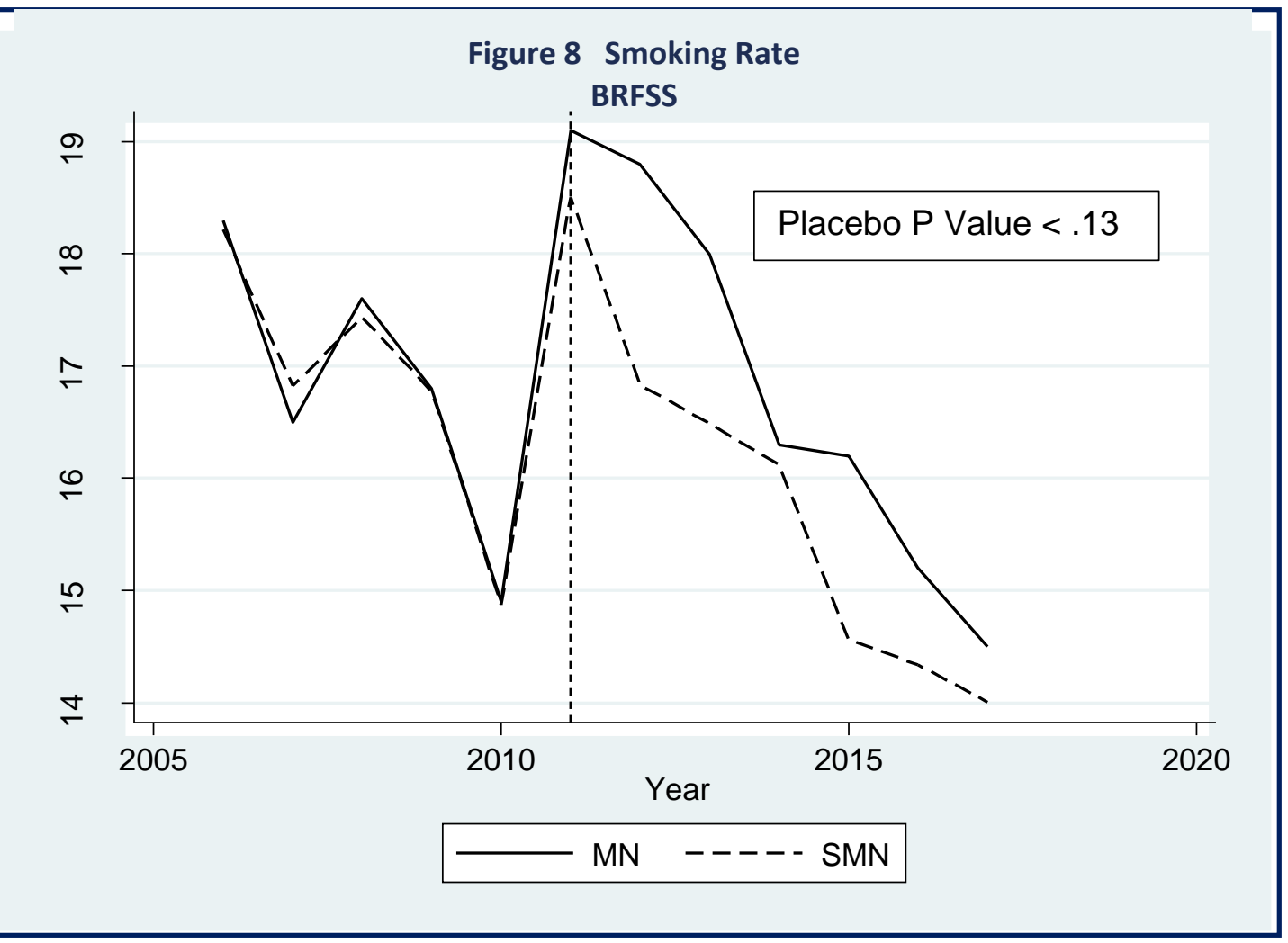

\section{Table 5}

Effect of the MN E-cigarette Tax on Smoking Rate from the BRFSS

DD: MN vs. Synthetic MN

\begin{tabular}{|c|l|c|c|c|c|}
\hline Model type & \multicolumn{1}{|c|}{ Data } & $\begin{array}{c}\text { Coefficient of } \\
\text { the treatment } \\
\text { variable }\end{array}$ & $\begin{array}{c}\text { Standard } \\
\text { Error }\end{array}$ & t-value & P-value \\
\hline DL1 & Levels & $1.0404^{\star \star \star}$ & 0.3124 & 3.33 & 0.008 \\
\hline DL2 & Year Differences & 0.5677 & 0.8457 & 0.67 & 0.517 \\
\hline
\end{tabular}

Figure 9

BRFSS Effects of Lagged Treatment Variables with 95\% confidence intervals

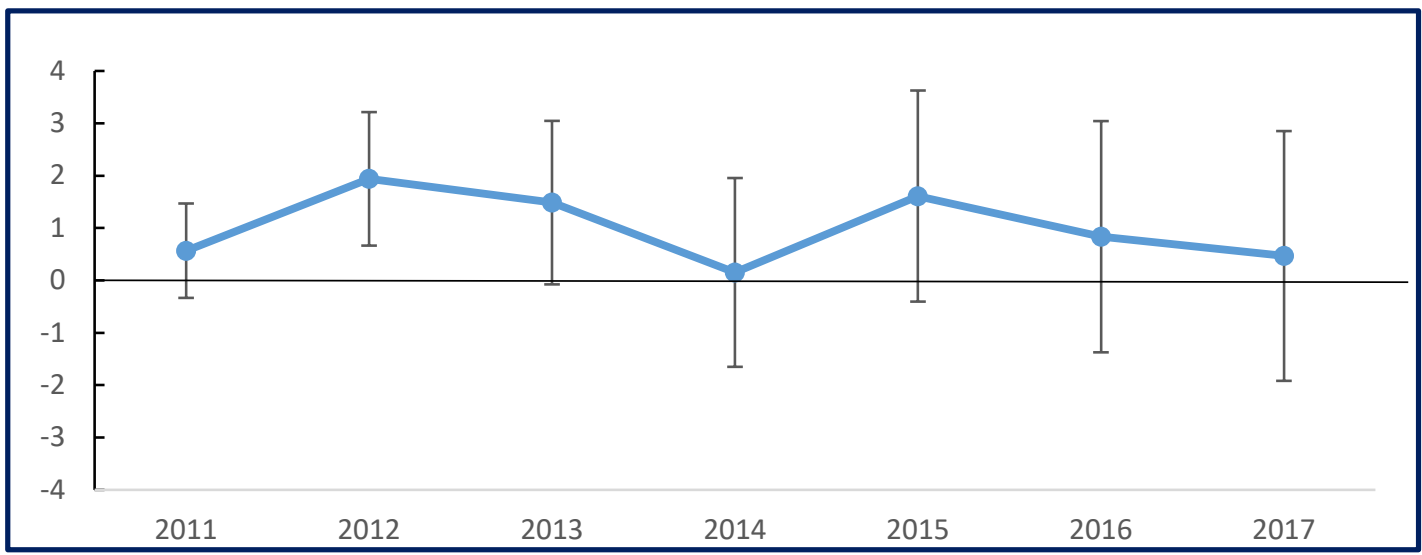

